\title{
Data Representation from Energy Balances by Using Geo-information System
}

\author{
Ivan L. Trofimov, Leonid N. Trofimov, Sergei V. Podkovalnikov \\ Melentiev Energy Systems Institute Siberian Branch of the Russian Academy of Sciences, \\ Lermontov str., 130 \\ Irkutsk, Russia \\ E-mail: t_john88@isem.irk.ru
}

\begin{abstract}
The article describes the software tool implemented by Melentiev Energy Systems Institute SB RAS and aimed to solving problems related to study prospective electric power systems. In this paper, the Data Processing and GeoInformation System (DPGIS) means a software tool that provides collection, transfer, processing, storage and output of digital technical and economic data of different power entities. These entities are represented in DPGIS as objects of special database. Low-level objects of DPGIS are power plants. Top-level objects are countries, power systems, and interstate power interconnections. The paper discusses the example of how data storage and data representation in object-oriented database assists to improve the efficiency of studying problems of prospective electric power systems expansion.
\end{abstract}

Keywords: Geo-information system, data processing, object-oriented database, power plant, electric power balance, electric power system.

\section{Introduction}

In research of prospective electric power systems expansion, the most laborious process is the processing of large volumes of data, collected from various Internet sources \& for different points and frames of time.

Similar problems of the data collection and processing concern researchers in many fields (Xuming, 2018). A lot of universal and specialized software was developed. In most cases, relational databases are using to the data storage. To process multidimensional data sets OLAP, Data Mining and others methods are used.

The issues of prospective electric power systems expansion and forecasting of electric power balances requires the data completeness, many mathematical, economic and special data transformations. To solve such problems, the using of universal methods for data storage and processing are not effective. Moreover, in many cases - it is impossible.

The most popular database management systems such as Firebird, Oracle, MS SQL and geo-information systems such as ArcGIS, MapInfo, Google Maps etc. do not assist researchers to solve specific issues. The problems dedicated to specific calculations of efficiency, forecasting and modeling of complex entities (power plants and power systems for the regions and countries levels), are described by a large set of various dynamic information. For this reason, a specialized decision support system ${ }^{*}$ is necessary to study problems of prospective electric power systems.

The authors propose an original technique of data storage and processing by object-oriented database (OODB). A specialized Data Processing and GeoInformation System (DPGIS) based on OODB has been developed (Podkovalnikov, 2018). DPGIS is integrated with various linear optimizers, and aimed at solve wide range of energy problems.

DPGIS infrastructure includes:

1) The interface unit to work with the optimization model ORIRES, which is used to make prospective power systems and interstate power interconnections (Chudinova, 2018).

2) The interface unit to study and forecast fuel and energy balances. This unit assists researchers to analyzing retrospective energy/power balances of countries and regions, and forecasting new energy/power balances.

3) The maps/cartographic unit is to construct interactive maps, with possible combination of various energy/power data diagrams, for different points and frames of time (Trofimov, 2017).

\footnotetext{
* Decision Support System (DSS) is an information system that supports business or organizational decision-making activities for experts.
} 
4) The Graph unit is to create complex graphs and diagrams for comparison and analysis of the retrospective energy/power statistics in different countries and regions.

5) The special Query Designer unit is to make and display various data tables, with built-in mathematical transformations (formulas for energy/power measures translating, interpolating missing values, maximum and minimum functions, data aggregation, and others).

The paper describes the example of the data storage and representation technique based on object-oriented database, which improves the efficiency of studying problems of forecasting energy and power balances

\section{The data storage technique based on object- oriented database}

The authors offer a new approach to organization of data storage and representation. They developed an object-oriented database. Low-level objects of this database are power plants with technical and economic data. Top-level objects of the database are countries, energy/power systems, and interstate power interconnections.

Each database object describes the properties of certain entities (power plants, power systems, countries etc.). OODB's object is a separate file, containing a set of properties and values of physical entity energy/power parameters and values, grouped by year, day and hour. In the same directory, there is an additional file, which contains a metadata about object types and others. Any text editor can be used to view OODB files system format (Trofimov, 2015).

The content of database objects is represented by dynamic editable tables in the interface unit to work with OODB. The table contains object parameters and its values, see Table 1 . The edited values are automatically recorded to object's format.

Table 1: A fragment of data on selected object

\begin{tabular}{|l|l|l|l|}
\hline Parameter & \multirow{2}{*}{$\begin{array}{l}\text { Parameter } \\
\text { name }\end{array}$} & \multicolumn{2}{|l|}{ Values stored by year } \\
\cline { 3 - 4 } nype & country & 1990 & \multicolumn{2}{|l|}{1991} & $\ldots$ \\
\hline tD & Russia & \\
\hline imp_coal & $\begin{array}{l}\text { Coal import } \\
\text { (ktoe) }\end{array}$ & $35087|28011| 23719 \mid \ldots$ \\
\hline exp_coal & $\begin{array}{l}\text { Coal export } \\
\text { (ktoe) }\end{array}$ & $40423|25525| 27867 \mid \ldots$ \\
\hline exp_oil & $\begin{array}{l}\text { Oil export } \\
\text { (ktoe) }\end{array}$ & $\begin{array}{l}222907|175271| 143161 \mid \\
\ldots\end{array}$ \\
\hline el_prod & $\begin{array}{l}\text { Electricity } \\
\text { production } \\
(\text { TWh })\end{array}$ & $1082|1069| 1062 \mid \ldots$ \\
\hline$\ldots$ & $\ldots$ & $\ldots$ \\
\hline
\end{tabular}

The technique of data storage and representation allows users to compactly store the whole data related to the certain entity. In addition, it is not necessary to create a set of auxiliary tables and indexes.

These entities are represented in OODB as objects. Text properties of objects are names, metadata, and links to external media (photos, videos and others). Numerical properties of objects can be separately store by year, day and hour - it depends from objects type. In this case, all necessary data that describes the entity are collected in one file. This guarantees data integrity and avoids the potential data loss (data fragmentation). By verification and data processing procedures, user can create various trends of numerical parameters values, even when object's name can differ for different sources. For example, on different Internet sites, the same power plant may have different name spellings.

Object-data representation allows user to compactly store large data of different object types, data collected for different points and frames of time, and from any sources. Special data processing procedures include methods for objects verification, algorithms for interpolating missing data, mathematical formulas for converting and combining various parameters. Work experience with various databases shows that such procedures are rather difficult to implement in standard SQL queries. At the Fig. 1 there is a OODB flowchart.

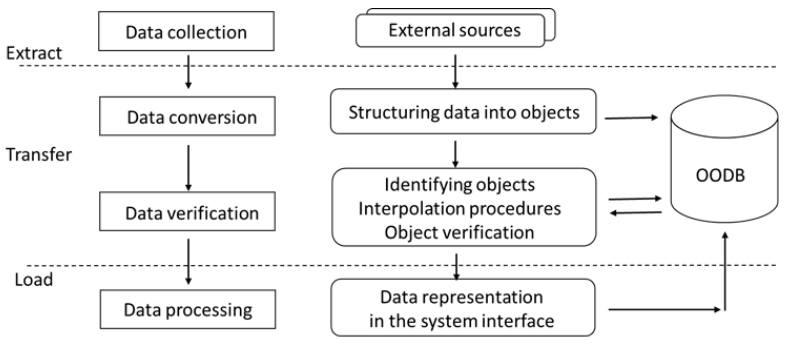

Fig. 1. OODB flowchart.

OODB operation consists in the following stages:

1. Collection of various non-systematized data from open sources;

2. Data restructuring to OODB format;

3. Data extracting from OODB;

4. Data processing in DPGIS interface - the making of interactive maps, graphs and diagrams, with the possibility of retrospective and prospective data analysis;

5. Export of processed data to external Analytical Internet Service ("Energy Statistical Analytical Service," 2017) in order to present results of the research for the scientific community and attracting the interest of the world community. 


\section{The data processing technique}

A special Query Designer for DPGIS was developed (Trofimov, 2014). With the Query Designer unit, users do not operate with SQL query concepts, but only need to create a table with required fields. Users do not depend on programmers, and they do not need specialized knowledge to construct complex SQL queries, see Fig. 2.

A special query technique consists of the following stages:

1) Building a query by using a set of special energy field concepts;

2) Reading/extracting data from OODB and performing the necessary mathematical data transformations;

3) Making results.

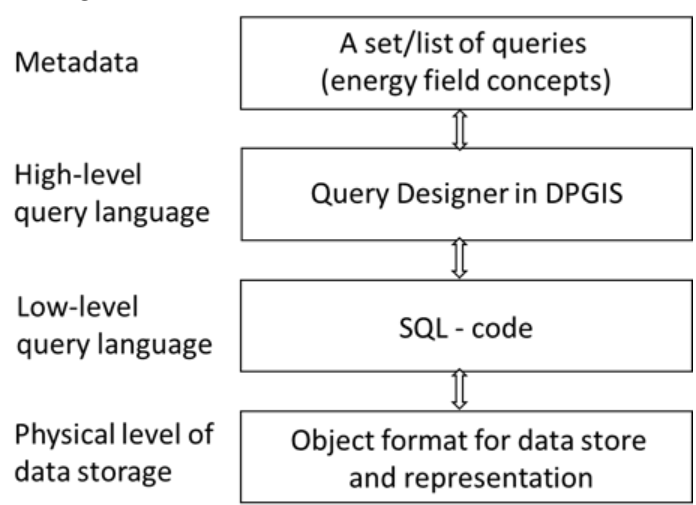

Fig. 2. Query levels to the database.

This approach allows users to generate comprehensive and parametrized queries, contains special calculations, such as interpolation of missing data of certain year, and other mathematical data transformations (addition, subtraction, multiplication, division, etc.).

The Query Designer unit allows users to get effective access to data without any assistance of programmers, without special skills to work with databases and specific knowledge for building SQL queries.

\section{The graph and the cartographic unit interfaces usage}

View one of examples of DPGIS interfaces usage is the analysis and forecasting of energy balances, and its representation in tabular and cartographic views. For comprehensive studies of prospective electric power systems expansion, it is necessary to conduct an express analysis of the fuel and energy balance (energy resources, energy consumption, fuel mix, etc.).

Considered are energy balance statistics distributed by the IEA ("International Energy Agency: Data Services," 2016). Information provided by the IEA contains retrospective data of energy balances of almost all countries in the world (more than 200 countries), starting from the 1970s. A multidimensional cube (OLAP-data representation) represents the data, see Fig. 3.

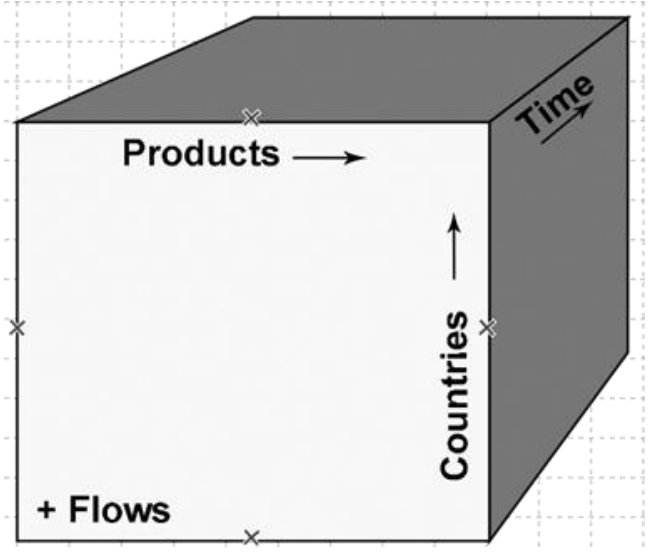

Fig. 3. Multidimensional data cube for energy balances of countries.

One of cube sections is energy balance of the country, for any year. Access to this data is possible only through a special application that allows users to view any slices of this cube. Data processing is limited by the application capabilities. In addition, to study electric power systems, it is necessary to choose only the electric power component from a huge array of data.

DPGIS developed by the authors, allows users to collect and restructure input data into the objectoriented storage. The entire volume of the above information was transferred into OODB. It was about 200 objects in OODB (by number of countries). The total amount of data received was about $10 \mathrm{MB}$, while original cube was about $100 \mathrm{MB}$. Data storage in object-oriented format allowed authors to expand possibilities of using this data for studying and forecasting fuel and energy balances.

DPGIS interface allows users to make balance tables for any country, and for any year from available retrospective data, see Table 2. All indicators given in Ktoe - Kiloton of oil equivalent. 
Table 2: The fragment of energy balance for South Korea, 2012 (Ktoe).

\begin{tabular}{|c|c|c|c|c|c|c|c|c|c|}
\hline & coal & crude & oil & gas & nuclear & hydro & electric. & heat & total \\
\hline Production & 932 & 718 & & 391 & 39176 & 341 & & 82 & 46215 \\
\hline Imports & 76079 & 131070 & 37436 & 42840 & & & & & 287425 \\
\hline Exports & & -356 & -58463 & & & & & & -58819 \\
\hline Stock changes & 69 & -927 & 318 & 1735 & & & & & 1194 \\
\hline $\begin{array}{l}\text { Total primary } \\
\text { energy supply }\end{array}$ & 77079 & 130505 & -33283 & 44966 & 39176 & 341 & & 82 & 263442 \\
\hline Transfers & & -3003 & 3131 & & & & & & 128 \\
\hline Electricity plants & -48543 & & -3366 & -16052 & -39176 & -341 & 40702 & & -67057 \\
\hline CHP plants & & & -194 & -5364 & & & 2296 & 1683 & -1618 \\
\hline $\begin{array}{l}\text { Autoproducer CHP } \\
\text { plants }\end{array}$ & -5910 & & -1705 & -657 & & & 2352 & 2810 & -3458 \\
\hline Blast furnaces & -9175 & & & & & & & & -9175 \\
\hline Gas works & & & -725 & 559 & & & & & -166 \\
\hline Oil refineries & & -136793 & 135192 & & & & & & -1601 \\
\hline $\begin{array}{l}\text { Petrochemical } \\
\text { plants }\end{array}$ & & 8117 & -7836 & & & & & & 281 \\
\hline $\begin{array}{l}\text { Energy industry } \\
\text { own use }\end{array}$ & -2897 & -12 & -4960 & -237 & & & -2799 & -83 & -10988 \\
\hline Losses & & & & & & & -1487 & -60 & -1547 \\
\hline $\begin{array}{l}\text { Total final } \\
\text { consumption }\end{array}$ & 9589 & & 84393 & 22897 & & & 41401 & 4973 & 166384 \\
\hline Industry & 8318 & & 4145 & 9290 & & & 21555 & 2128 & 47327 \\
\hline Transport & & & 28594 & 1149 & & & 194 & & 30241 \\
\hline $\begin{array}{l}\text { Other (Residential, } \\
\text { Commerce) }\end{array}$ & 816 & & 8695 & 12459 & & & 19652 & 2845 & 45401 \\
\hline Non-energy use & 455 & & 42959 & & & & & & 43414 \\
\hline
\end{tabular}

We have developed special cartographic unit to make forecasts of energy balances of prospective year, by using a linear optimizer. For any country, it is possible to make a forecast of energy balance, including its electric power component.

As a result, it is possible to make energy balance tables by using DPGIS both in retrospective data and in calculated to prospective year.

The authors supplemented OODB with geographical coordinates to objects-countries. Then, by using cartographic unit, it is possible to display energy balance indicators as pie charts on the map, for any region in the world. The map is created with automated mode, and users can view indicator's changes for different years. In addition, there is a mode of exporting constructed maps to a special Web application ("Energy Statistical Analytical Service," 2017).

For example, the interactive map shows electricity component of energy balance sheet - electricity production for all countries in the world (Fig. 4). Electricity production is given in TWh - Terawatt hours. Sizes of pie charts are proportional to amount of electricity produced.
Another example of data representation by DPGIS interface is a graph making. The same indicator of electricity production can be presented on the combined

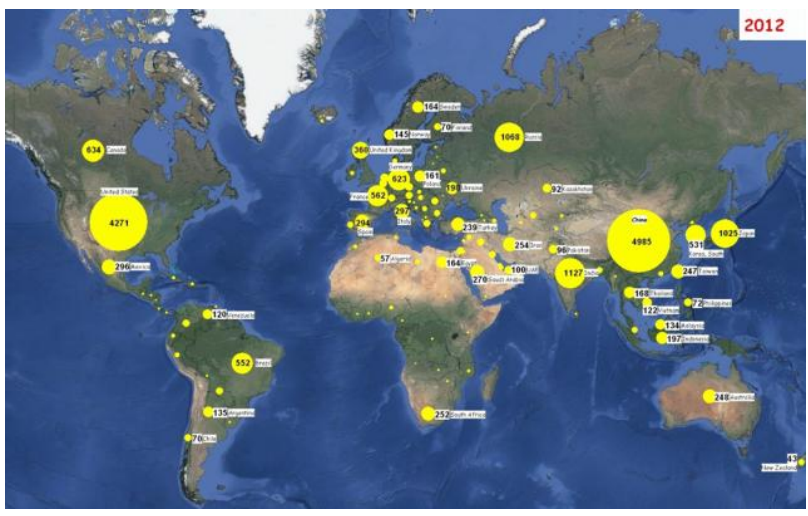

Fig. 4. World electricity production, 2012 (TWh).

graph, reflecting the growth dynamics of ten largest electricity-producing countries from 1990 to 2012, see Fig. 5.

In 2012, China and the US together produced $41 \%$ of the total electricity in the world. United States electricity production increased quite modestly (from 
3203 TWh in 1990 - to 4271 TWh in 2012), at the same time electricity production in China increased by more than 8 times (from 594 TWh in 1990 - to $4985 \mathrm{TWh}$ in 2012).

In addition to data showed in examples, OODB contains many other data collected from various sources. For example, data collected from open resource

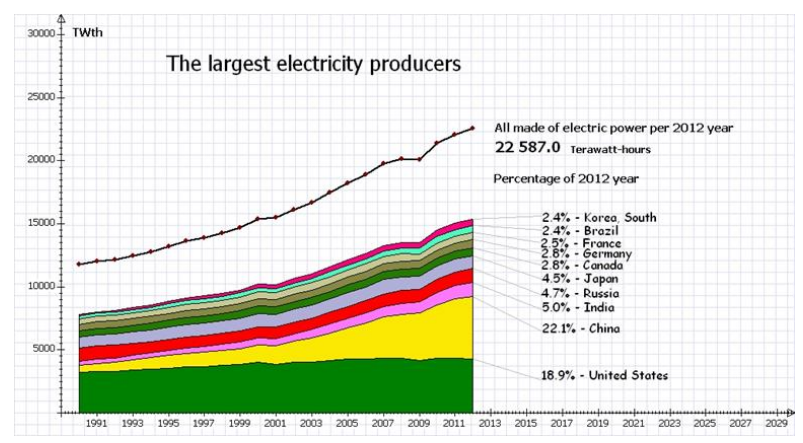

Fig. 5. Graph of 10th largest electricity producers in the world.

Enipedia.org ("Energy Pedia Portal," 2017), that contains technical and economic indicators for different countries. These indicators are capacity of power plants, geographic coordinates, volumes of production and consumption, exports and imports, etc. The cartographic unit allows users to make power plant maps with coordinates, connections, volumes, capacity types and others.

The data storing technique based on object-oriented database, and data processing by graphical interfaces of DPGIS, considered in this paper, are universal for solving many problems in energy sector.

\section{Conclusion}

Among constantly changing databases and information systems offered on the market, there are specialized decision support systems, especially in case when it is necessary to have a compact data structure and transparently store information. In this case, the procedures for extracting, processing and data visualizing must have a universal interfaces that can be customized for various issues related to study prospective electric power systems.

The authors propose a new, modern approach to analyze and process a large volume of data. The main components (units) of DPGIS related to solving problems of energy/power systems expansion have been developed.
The proposed technique of storing and processing data, based on object-oriented database greatly simplifies calculations, reduces time for making forecasts in energy/power sector, and makes it possible to increase reliability of research results.

DPGIS is a kind of decision support system, and related to improve efficiency of studied problems of prospective electric power systems and improve quality of optimization models solutions by using convenient interfaces.

\section{Acknowledgements}

The paper was carried out under financial support of the RFBR grant (Russian Foundation for Basic Research) No. 18-07-00495 A.

\section{References}

1. Xuming, L. (2018). Application and research of global grid database design based on geographic information. Global Energy Interconnection Development and Cooperation Organization, 1 (1), 87-95B. Widrow and S. D. Steams, Adaptive Signal Processing (Prentice Hall, Englewood, NJ, 1995).

2. Podkovalnikov, S., Trofimov, I., \& Trofimov, L. (2018). Data processing and optimization system to study prospective interstate power interconnections, in Proceedings of the 10th International Conference on Asian Energy Cooperation (AEC 2017), (Irkutsk: E3S Web of Conf.) 27, 32-40.

3. Chudinova, L., Podkovalnikov, S., \& Trofimov, I. (2018). Multilateral cooperation for power interconnection in Northeast Asia, in Proceedings of the 10th International Conference on Asian Energy Cooperation (AEC 2017) (Irkutsk: E3S Web of Conf.) 27, 20-28.

4. Trofimov, I., \& Trofimov, L. (2017). Modern problems of data search and data verification on power plants in China and other countries, J. Information and mathematical technologies in science and management, 4(8) 120-128.

5. Trofimov, L., \& Trofimov, I. (2015). Internet service for the analysis of statistical data in the field of energy on the example of the world oil market, In Proceedings of the conference "Energy of Russia in the XXI century. Innovative development and management" (Irkutsk, MESI SB RAS, 2015) pp. 170-174.

6. Energy Statistical Analytical Service: ESAS. World Energy on interactive maps. (2017, December 10). Retrieved from http://esas.com.ru/en/

7. Trofimov, I. (2014). Using metadata to query the database on thermal economy of Russia through the Internet, in Proceedings of the 10th International 
Conference Mathematical and Informational Technologies (MIT-2013), (Vrnjacka Banya) pp. 706-714.

8. International Energy Agency: Data Services. (2016, February 24). Retrieved from http://wds.iea.org/WDS/Common/Login/login.aspx

9. Energy Pedia Portal: Power Plants. (2017, November 15). Retrieved from

https://enipedia.org/wiki/Portal:Power_Plants/ 